\section{DEM-based Feature Information Index of Runoff Nodes}

Gl_Forum 2016, Vol.2

Page: 67-73

Full Paper

Corresponding Author:

fuyanghuzui@163.com

DOI: 10.1553/giscience2016_02_s67

\author{
Zui Hu',2 and Josef Strobl2 \\ 1 Hengyang Normal University, Hunan Province of China \\ 2 University of Salzburg, Austria
}

\begin{abstract}
Runoff nodes, located where stream segments merge to form a larger one, carry important structural geographic information. Extensive research has been done on runoff nodes, but there is still a lack of work on measuring the information content of runoff nodes across watersheds. This paper develops a novel index, called the "Feature Information Index of Runoff Nodes" (FIIRN), to assess the feature information content according to the Theory of Rough Sets (TRS). Firstly, this paper establishes the conception of, and the algorithm behind, FIIRN. Then, by exploring seven typical landforms of the Loess Plateau of China as case studies, values of FIIRN are calculated after extracting all the runoff nodes. Our experiment shows that FIIRN can effectively represent the feature information of watersheds, such as runoff order or evolutionary status. In summary, FIIRN will play a significant role in future watershed analysis.
\end{abstract}

\title{
Keywords:
}

digital elevation models, watershed analysis, runoff nodes

\section{Indroduction}

Runoff nodes, located where streams merge to form a larger one (Yi et al., 2003; Li, J. F. et al., 2005a), are a physical geographical entity on the earth's surface. Runoff nodes play a pivotal role in capturing the watershed characteristics, thanks to their extensive morphological information content (Zhu et al., 2012). Recently, multiple publications have documented the extraction methods for crucial properties, watershed partitioning algorithms, identification feature points (e.g. the head of channels), and their topological relationships (Jiang et al., 2013; Qian et al., 2013; Liu T. et al, 2013; Xie et al., 2013; Sun \& Tang, 2013; Li, Y. S., 2013; Lin et al., 2008; Wilson, 2012; Iwahashi \& Pike, 2007). The existing literature, however, mainly focuses on geomorphologic structures in watersheds, on hydraulic information (Xie et al., 2013; Sun \& Tang, 2013; Li, Y. S., 2013; Lin et al., 2008; Wilson 2012; Iwahashi \& Pike, 2007; Li, J. F. et al., 2005b; Wang 2012; Zhou \& Liu, 2006; Liu, X. et al., 2011; Li, D. R. et al., 2008), and on energetic features (Liu, T. et al., 2013). Nevertheless, there is substantial interest in the information content of runoff nodes. In fact, runoff nodes are considered to represent the evolutionary processes of watersheds prominently, as they 
reflect the stream order, represent drainage density (Vogt et al., 2003), and describe different evolutionary stages of runoff network development. Furthermore, we can more fully assess watersheds by considering runoff nodes. To date, there has been insufficient research on quantitatively extracting the feature information of runoff nodes from digital elevation models (DEM). Aiming to address this lack, this paper focuses on calculating the information content of runoff nodes in watershed analysis, defines a Feature Information Index of Runoff Nodes (FIIRN) by using the Theory of Rough Sets (TRS), and tests the performance of FIIRN with a case study.

\section{Data preparation}

The Loess Plateau of China is the most typical loess landform in the world due to its intact geomorphological sequences, and as such it has received increasing attention (Xiong et al., 2014). The present study uses the Sheng mu, Sui de, Yan chuan, Gan quan, Yi jun, Chun hua and Chang wu for case studies (Figure 1a), for the following reasons: (1) the study areas should cover both intact sequences and morphological diversity; (2) the landform types of case areas should closely approach the sequence from "Huang Tu Mao" to "Huang Tu Liang", and to "Huang Tu Yuan".

By using ArcGIS, MATLAB and Excel, the workflow illustrated in Figure 1b was designed: (1) extracting the runoff nodes from DEM, and (2) calculating the FIIRN. The data used in this study are projected using a Gauss-Krüger projection, and referenced in the Chinese XI'AN 1980 coordinate system. A 5-metre grid resolution for the DEM was used.

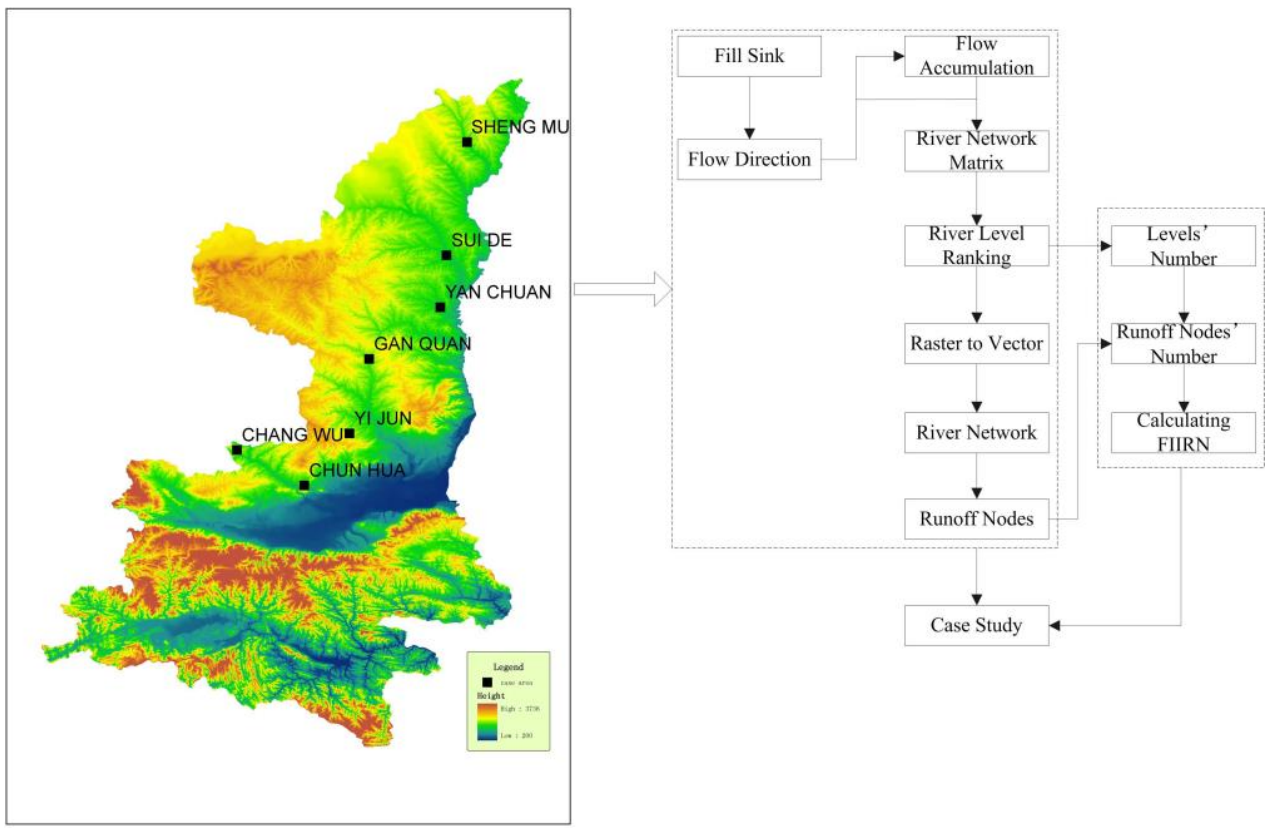

Figure 1: Experiment outline: 1 (a) overview map of the case study area; 1 (b) the analysis sequence performed using ArcGIS software. 
For a given region, we can easily derive the stream (gully) density from the DEM by: (1) extracting the gullies from the DEM; (2) calculating the total length of the gullies; (3) calculating the total area of the study area; (4) establishing the gully density according to the definition of gully/drainage density (Melton, 1957). Table 1 shows the results obtained.

Table 1: The gully density of the case study area

\begin{tabular}{|l|l|l|l|l|l|l|l|}
\hline \multirow{2}{*}{ Unit } & \multicolumn{6}{l|}{ Case area } \\
\cline { 2 - 8 } & Sheng mu & Sui de & Yan chuan & Gan quan & Yi jun & Chang wu & Chun hua \\
\hline $\mathrm{km} / \mathrm{km}^{2}$ & 3.4 & 5.34 & 6.78 & 5.60 & 5.20 & 3.13 & 3.15 \\
\hline
\end{tabular}

\section{Methods}

\section{Feature Information of Runoff Nodes}

Different geomorphological states and the changes in evolutionary processes of watersheds exhibit ample geospatial information, with some important distinctions. From the perspective of geomorphologic structural features (Zhu et al., 2012), runoff nodes are linked to information such as hydraulic dynamics, the status of evolutionary landscape processes, stream order, morphological features, and flow accumulation (Table 2). Various watershed parameters are closely related to runoff nodes, such as river network density, average relief of watershed, and flow routing through watershed. Thus, runoff nodes are considered important information resources for watersheds.

Table 2: Information attached to runoff nodes

\begin{tabular}{|l|l|}
\hline Information types & Information details \\
\hline Hydraulic relief information & The hydraulic relief between origins and outlets \\
\hline Evolutionary status information & $\begin{array}{l}\text { Indicating different evolutionary status/stage of sub- } \\
\text { watershed }\end{array}$ \\
\hline Ranking information of rivers & $\begin{array}{l}\text { Runoffs at different volume merge themselves into the same } \\
\text { trunk }\end{array}$ \\
\hline Morphological features & $\begin{array}{l}\text { Distribution pattern of runoff nodes maps the morphological } \\
\text { features of the watershed as a whole }\end{array}$ \\
\hline Flow accumulation & Collecting all the flows of the catchment \\
\hline
\end{tabular}

\section{Representation of runoff nodes using Theory of Rough Set (TRS)}

The physical characterization of a watershed has to deal with vagueness and uncertainties, such as calculating the azimuthal direction of a slope (Kenny et al., 2008). Nevertheless, TRS, which is derived from set theory in mathematics (Pawlak, 1982), can help to deal with this 
problem as it provides a new mathematical toolkit for extracting useful information from data without requiring any prior knowledge and experience. In fact, it is commonly accepted that TRS is effective in dealing with imprecision, vagueness and uncertainty (Pawlak, 1997).

First, let us shed light on the feature information of runoff nodes if we use TRS. Considering $\mathrm{R}$ as a limited domain and $\mathrm{P}(\mathrm{x})=2^{\mathrm{R}} \rightarrow[0,1]$ as a probability density function, the potential probabilities of $\mathrm{R}$ can be described by Formula 1 :

\section{$p_{i}=P\left(x_{i}\right) \operatorname{per} x_{i} \quad($ Formula 1$)$}

Here, $p_{i}$ is a probability distribution of $\mathrm{R}$.

A watershed can also be treated as a geometric network (Liu, X. et al., 2011). If likened to an information network, runoff nodes can be considered as the switches of the geographical information, and streams can be considered as the geographical information pipelines.

Considering $\mathrm{L}$ as the stream-level set of all the runoffs of $\mathrm{R}, \mathrm{N}$ is the number of runoff nodes at each level. According to TRS, every level represents an equivalent class of R. So, we obtain a cluster of equivalent classes: $L_{i}=\left\{l_{1}, l_{2}, \cdots, l_{n}\right\}$, here, $L_{i} \subset R, L_{i} \neq \phi$. Hence, $L_{i}$ is a subset of R:

$$
R / L_{i}=\left\{x_{1}, x_{2}, \cdots\right\} \quad \text { (Formula 2) }
$$

According to Formulas 1 and 2, within the domain $\mathrm{R}$, the cluster of equivalent classes $\mathrm{L}_{\mathrm{i}}$ can reflect the information content of runoff nodes in a watershed. Note that differences among all the physical states of watersheds are neglected in this study on the basis of mathematical rules of TRS. For example, relief, flow accumulation and flow power are different states in a watershed, but this study views them as fluvial geographical information without their own physical properties.

\section{Definition of Feature Information Index of Runoff Nodes}

In order to measure the information content of runoff nodes within watersheds, we employ TRS. Considering (as in section 3.2) $\mathrm{L}$ as the overall level of runoff of $\mathrm{R}, \mathrm{L}_{\mathrm{i}}$ as the specific levels of the runoff in $R$, and $m(m \in N)$ as the corresponding number of runoff nodes, we can assess the values of FIIRN for level $\mathrm{L}_{\mathrm{i}}$ as follows:

$$
\text { FIIRN }_{L_{i}}=\log _{2} m \quad \text { (Formula 3) }
$$

To determine the total information content of runoff nodes across the entire watershed, we can add up the values of FIIRN for each level. 


\section{$4 \quad$ Results and Analysis}

Table 3 presents the results from extracting runoff nodes within the study areas introduced in Figure 1; Table 4 shows the computation results of FIIRN.

For a given region, a runoff node can present some crucial geomorphologic features. As seen in Figure 2, there is obviously a linear correlation between stream order rank and the number of nodes. From this case study, we can confirm the following: (1) values of FIIRN show a positive correlation with stream order; (2) the FIIRN value is in line with the gully density; and (3) from north to south across the Loess Plateau, with the landforms changing from hilly to plane, the FIIRN values show a decreasing trend. Hence, FIIRN depicts a macro-scale trend of landforms.

The above results show that the definition and characteristics of FIIRN can be verified well by the results of experiments. Undoubtedly, FIIRN as introduced here can be employed as a useful tool to evaluate the information content of runoff nodes for a given watershed.

Table 3: Extraction results of the runoff nodes of each case

\begin{tabular}{|l|l|l|l|l|l|l|l|}
\hline \multirow{2}{*}{ Rank } & \multicolumn{6}{l}{ Extraction results } \\
\cline { 2 - 8 } & Sheng mu & Sui de & Yan chuan & Gan quan & Yi jun & Chang wu & Chun hua \\
\hline I & 217 & 275 & 262 & 231 & 181 & 208 & 160 \\
\hline II & 133 & 170 & 172 & 118 & 143 & 61 & 109 \\
\hline III & 47 & 59 & 106 & 59 & 62 & 69 & 78 \\
\hline IV & 33 & 47 & 12 & 16 & - & 23 & 4 \\
\hline Total & 430 & 551 & 552 & 424 & 386 & 361 & 351 \\
\hline
\end{tabular}

Table 4: FIIRN values of each case

\begin{tabular}{|l|l|l|l|l|l|l|l|}
\hline \multirow{2}{*}{ Rank } & \multicolumn{6}{l}{ FIIRN's value (bit) } \\
\cline { 2 - 8 } & Sheng mu & Sui de & Yan chuan & Gan quan & Yi jun & Chang wu & Chun hua \\
\hline I & 7.761 & 8.1033 & 8.033 & 7.851 & 7.498 & 7.700 & 7.321 \\
\hline II & 14.816 & 15.512 & 15.459 & 14.734 & 14.658 & 13.631 & 14.090 \\
\hline III & 20.371 & 21.395 & 22.187 & 20.616 & 20.612 & 19.739 & 20.375 \\
\hline IV & 25.875 & 26.949 & 25.772 & 24.616 & - & 24.263 & 22.375 \\
\hline Watershed & 25.415 & 26.949 & 25.772 & 24.617 & 20.613 & 24.263 & 22.375 \\
\hline
\end{tabular}




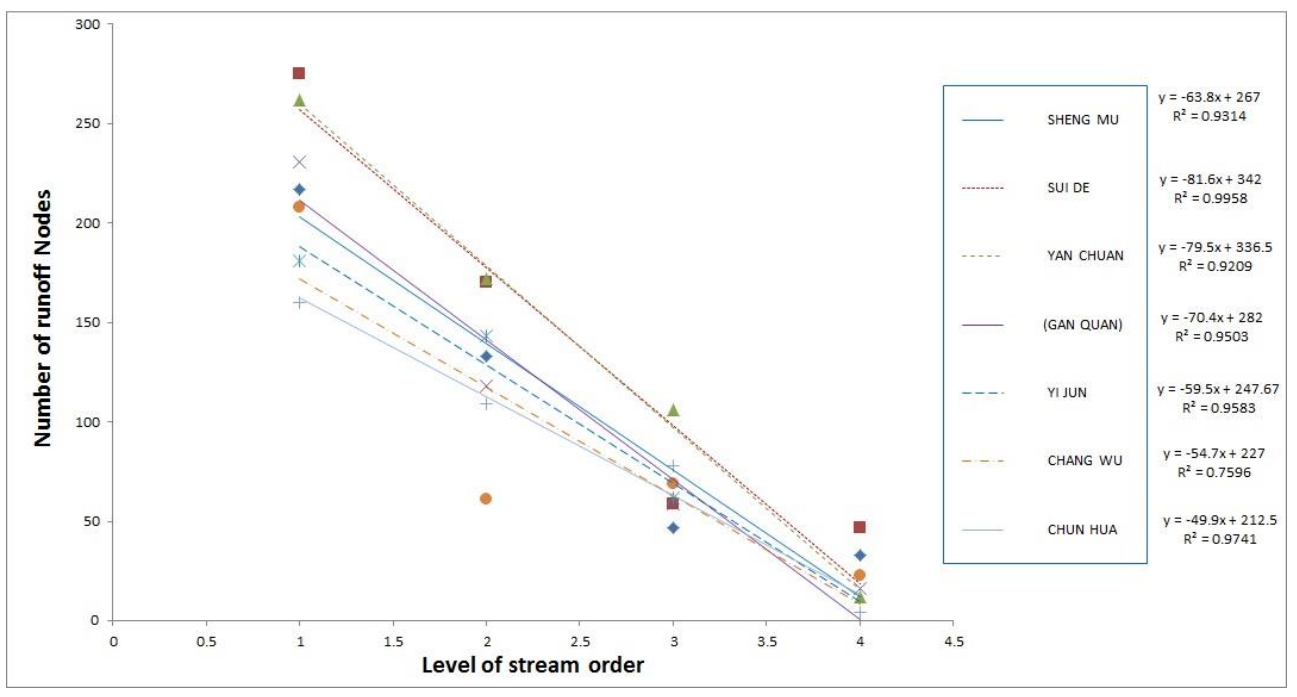

Figure 2: Linear correlation between rank of runoff and number of nodes.

\section{Conclusions}

In this study, the Feature Information Index of Runoff Nodes (FIIRN) was developed as an index for measuring the feature information content of runoff nodes in a given watershed by introducing the Theory of Rough Sets. FIIRN can work well when used to extract the information features throughout sample areas. This experiment shows that FIIRN can represent succinctly the features of watersheds, such as stream order or stage of evolution. Hence, FIIRN has the potential to play a pivotal role in watershed analysis in the future.

\section{Acknowledgements}

This work was supported by the Nature and Science Foundation of China (NFSC) under Grant 41201398, and by the Joint Excellence in Science and Humanities (JESH) of Austria under Grant 2014-005.

\section{References}

Iwahashi J. \& Pike R. J. (2007), Automated classifications of topography from DEMs by an unsupervised nested-means algorithm and a three-part geometric signature. Geomorphology, 86(34), 409-440.

Jiang, L., Tang, G. A. \& Zhao, M. W. (2013), Extraction and analysis of Loess gully heads considering geomorphological structures. Geographical Research, 32(11), 2153-2162.

Kenny, F., Matthews, B. \& Todd, K. (2008), Routing overland flow through sinks and flats in interpolated raster terrain surfaces. Computers \& Geoscience, 34, 1417-1430. 
Li, D. R., Wang, S. L. \& Li, D. Y. (2008), Theory and Application of Spatial Data Mining. Beijing, Science Press.

Li, F. Y., Tang, G. A., Yan, S. J. \& Zhu S. J. (2013), Digital Elevation Models Experimental Instruction. Beijing, Science Press.

Li, J. F., Li, T. W., Chen, Z. J., Liu, X. J. \& Tang G. A. (2005a), Research on channel network nodes based on DEM in hill and gully area of the Loess Plateau. Arid Land Geography, 28(3), 386-391.

Li, J. F., Li, T. W., Tang, G. A. \& Liu X. J. (2005b), Research of water accumulation of channel Network Nodes Based on DEM. Journal of Mountain Science, 23(2), 228-234.

Li, Y. S. (2013), Construction and Analysis on the Structural Model of Gull Feature Points Cluster. Unpublished MSc Thesis, Northwest University, Xi'an.

Lin, W. T., Chou, W. C., Lin, C. Y. \& Tsai J. S. (2008), Win Basin: using improved algorithms and the GIS technique for automated watershed modeling analysis from digital elevation models. International Journal of Geographical Information Science, 22(1), 47-69.

Liu, T., Zhao, J. M., Gong, D. H. \& Qian, X. J. (2013), Extraction analysis on fracture nodes based on energy accumulation. Ground Water, 35(11), 159-160.

Liu, X., Wang, L. \& Gao, P. L. (2011), Extraction of stream runoff nodes based on geometric network. Science of Surveying and Mapping, 36(5), 85-86, 72.

Melton, M.A. (1957), An Analysis of the Relations among Elements of Climate, Surface Properties, and Geomorphology. Technical report, Department of Geology, Columbia University.

Pawlak, Z. (1982), Rough sets. International Journal of Computer and Information Sciences, 11, 341 356.

Pawlak Z. (1997), Rough set approach to knowledge-based decision support. European Journal of Operational Research, 99, 48-57.

Qian, K. J., Zhu, H. C. \& Li. F. Y. (2013), A method of deriving stream runoff nodes based on accumulation from DEM. Science of Surveying and Mapping, 37(1), 28-29, 59.

Sun, J. W. \& Tang G. A. (2013), Inter-watershed and its automatic extraction based on DEM. Journal of Geo-Information Science. 15(6), 871-878.

Vogt, J. V., Colombo, R. \& Bertolo F. (2003), Deriving drainage networks and catchment boundaries: a new methodology combining digital elevation data and environmental characteristics. Geomorphology, 53(3-4), 281-298.

Wang, M. Q. (2012), Research on extraction of hydrological elements and building topography structure of stream networks based on DEM: A case study in Yanhe Basin. Unpublished Master's Dissertation, Northwest University, Xi'an.

Wilson, J. P. (2012), Digital terrain modeling. Geomorphology, 137, 107-121.

Xie, Y. Q., Zhu, H. C., Tang, G. A. \& Zeng, R. A. (2013), Extraction and analysis of gully feature points based on DEM. Journal of Geo-Information Sciences, 15(1), 61-67.

Xiong, L. Y., Tang, G. A., Li, F. Y., Yuan, B. Y. \& Lu Z. C. (2014), Modeling the evolution of loesscovered landforms in the Loess Plateau of China using a DEM of underground bedrock surface. Geomorphology, 209, 18-26.

Yi, H. W., Tang, G. A., Liu, Y. M., Yang, X. \& Zhu, H. C. (2003), Stream runoff nodes and their derivation based on DEM. Journal of Soil and Water Conservation, 17(3), 108-111.

Zhou Q. M. \& Liu X. J. (2006), Digital Terrain Analysis. Beijing, Science Press.

Zhu, H. C., Tang, G. A., Wu, L. C. \& Qian, K. J. (2012), Extraction and analysis of gully nodes based on geomorphological structures and catchment characteristics: A case study in the Loess Plateau of north Shaanxi province. Advances in Water Sciences, 23(1), 7-13. 